\title{
AS DUAS COREIAS NOS QUADRINHOS: REPRESENTAÇÃO DOS PAÍSES NO OLHAR DO OCIDENTE ${ }^{1}$
}

\author{
Celbi Vagner Melo Pegoraro ${ }^{2}$
}

\begin{abstract}
RESUMO: O presente trabalho analisa a representação na visão ocidental da República da Coreia (Coreia do Sul) e da República Popular Democrática da Coreia (Coreia do Norte) em dois momentos históricos distintos. O universo de pesquisa abrange duas publicações em quadrinhos, cada qual focando um desses momentos. O italiano Romano Scarpa produziu uma saga "Seul 88", em oito capítulos, tratando com humor e utilizando personagens Disney para descrever um romance envolvendo personagens nativos das duas Coreias. Foi publicado no Brasil em agosto de 1988, às vésperas dos jogos olímpicos. Lançado em 2004, a graphic novel "Pyongyang: Uma Viagem à Coreia do Norte" do canadense Guy Delisle, apresenta um retrato irônico e crítico da Coreia do Norte, fruto de sua experiência de dois meses trabalhando como supervisor num estúdio de animação francês (que terceirizou a mão de obra), testemunhando o controle rígido e autoritário de seus anfitriões. O objetivo é verificar como os países são retratados em relação ao período histórico. Como metodologia será adotada a análise comparativa da representação visual e do estilo narrativo. Serão confrontadas as diferentes características político-ideológicas presentes em cada produção em relação ao período retratado.
\end{abstract}

PALAVRAS-CHAVE: Coreia; História em Quadrinhos; Cultura e Sociedade.

\section{THE TWO KOREAS IN THE COMICS: REPRESENTATION OF ASIAN COUNTRIES IN THE WEST'S EYES}

ABSTRACT: This paper analyzes the representation in the western view of the Republic of Korea (South Korea) and the Democratic People's Republic of Korea (North Korea) at two distinct historical moments. The research comprises two comic books, each focusing on one of these moments. Italian Romano Scarpa produced a saga "Seoul 88" in eight chapters, dealing with humor and using Disney characters to describe a novel involving characters native to both Koreas. It was published in Brazil in August 1988, on the eve of the Olympic Games. Released in 2004, Guy Delisle's graphic novel "Pyongyang: A Journey to North Korea" features an ironic and critical portrait of North Korea as a result of his two-month experience working as a supervisor in a French animation studio that outsourced the labor force, witnessing the rigid and authoritative control of their hosts. The objective is to verify how the countries are portrayed in relation to the historical period. As methodology will be adopted the

\footnotetext{
${ }^{1}$ O presente trabalho foi realizado com apoio da Coordenação de Aperfeiçoamento de Pessoal de Nível Superior - Brasil (CAPES).

${ }^{2}$ Doutor em Ciências da Comunicação pela Escola de Comunicações e Artes da Universidade de São Paulo (USP). Realiza estágio Pós-Doutoral no Programa Diversitas da FFLCH/USP.
} 
comparative analysis of visual representation and narrative style. The different politicalideological characteristics presented in each production will be confronted in relation to the period portrayed.

KEYWORDS: Korea; Comics; Culture and Society.

\section{LAS DOS COREAS EN LOS CÓMICS: REPRESENTACIÓN DE LOS PAÍSES EN LA VISIÓN DE OCCIDENTE}

RESUMEN: El presente trabajo analiza la representación en la visión occidental de la República de Corea (Corea del Sur) y de la República Popular Democrática de Corea (Corea del Norte). El universo de investigación abarca dos publicaciones en cómics, cada uno enfocando uno de esos momentos. El italiano Romano Scarpa produjo una saga "Seúl 88", en ocho capítulos, tratando con humor y utilizando personajes Disney para describir un romance envolviendo personajes nativos de las dos Coreas. Fue publicado en Brasil en agosto de 1988, en vísperas de los juegos olímpicos. En el 2004, la novela gráfica "Pyongyang: un viaje a Corea del Norte" del canadiense Guy Delisle, presenta un retrato irónico y crítico de Corea del Norte, fruto de su experiencia de dos meses trabajando como supervisor en un estudio de animación francés (que tercerizó la mano de obra), testimoniando el control rígido y autoritario de sus anfitriones. El objectivo es verificar cómo los países son retratados en relación al período histórico. La metodología se convertirá en un análisis comparativo de la representación visual y del estilo narrativo. Sería confrontado como diferentes características político-ideológicas presentes en cada producción en relación a un período retratado.

PALABRAS CLAVE: Corea; Historias en Cuadriños; Cultura y Sociedad.

\section{INTRODUÇÃO}

Toda produção cultural apresenta uma mensagem ideológica, ainda mais se relacionada a contextos políticos específicos que exacerbam certas características. $\mathrm{Na}$ teoria das relações internacionais há o conceito de "ator" no cenário mundial, ou seja, um Estado ou órgão internacional que age em prol de seus próprios interesses.

Ao estudar a política mundial, usamos tipicamente o termo ator para nos referirmos aos agentes que são os principais atores do mundo. Esses atores transnacionais incluem países (por exemplo, os Estados Unidos e o Japão), organizações internacionais (as Nações Unidas e o Conselho Nórdico), bem como atores não estatais, como organizações internacionais não-governamentais (a World Wildlife Federation), 
nacionalidades indígenas (os curdos no Irã, Iraque e Turquia), corporações multinacionais (Wal-Mart e Sony) e grupos terroristas (a rede global Al Qaeda).A imagem convencional é a de um palco em que os atores do drama global desempenham seus papéis atribuídos. Os principais atores dominam o centro do palco, e os atores coadjuvantes se movem ao longo da periferia (KEGLEY e WITHKOPH, 2006, p. 57, tradução nossa).

O extremo dessa ação visando interesses nacionais é o chamado hard power (poder bruto) cujo maior exemplo são as guerras e as sanções. A situação de conflito entre as Coreias está dentro do contexto da Guerra Fria quando, após a Segunda Guerra Mundial, o destino da nação foi definido pela ação das grandes potências vitoriosas, que agora se enfrentavam num conflito entre capitalismo e comunismo (ARRIGHI, 1996).

$\mathrm{Na}$ Conferência de Potsdam, os Aliados decidiram unilateralmente dividir a Coreia sem a consulta do povo coreano. A fronteira entre os dois países é limitada pelo Paralelo 38N (WAACK, 2008, p. 269). A Guerra da Coreia ocorreu entre 1950 e 1953, a partir da invasão da Coreia do Sul pelos norte-coreanos. Os Estados Unidos e as Nações Unidas entraram no conflito ajudando a Coreia do Sul. A China e a União Soviética prestaram apoio político e logístico para a Coreia do Norte. Sem a possibilidade de um dos lados ganhar uma batalha sobre o outro a ponto de decidir a guerra, uma longa negociação resultou no armistício em 1953.

As potências nucleares se envolveram em três grandes guerras (mas não umas contra as outras). Abalados pela vitória comunista na China, os EUA e seus aliados (disfarçados como Nações Unidas) intervieram na Coreia em 1950 para impedir que o regime comunista do Norte daquele país se estendesse ao Sul. O resultado foi um empate (HOBSBAWN, 1995, p. 234).

Para a nossa análise o conceito apropriado é o de soft power (poder brando), termo usado na teoria de relações internacionais para descrever a habilidade de um corpo político, como um Estado, para influenciar indiretamente o comportamento ou interesses de outros corpos políticos por meios culturais ou ideológicos. O cinema hollywoodiano é um exemplo de soft power dos Estados Unidos. O termo foi usado pela primeira vez na década de 1980 por Joseph Nye - professor de Harvard (NYE, 2005).

Na década de 1980, a Coreia do Sul (República da Coreia) promoveu todo o seu soft power utilizando os Jogos Olímpicos de Seul em 1988 como ponta de lança na 
divulgação de uma nova imagem do país, vendendo eficiência e inovação tecnológica. Na década de 2000, a Coreia do Norte estava inserida no chamado "Eixo do Mal" promovido pelo então presidente George W. Bush (EUA), incluído países como Irã e Síria, e iniciava uma atuação política mais provocativa em relação as potências do ocidente.

Apresentamos aqui uma análise de duas produções em histórias em quadrinhos que apresentam casos de representação envolvendo as duas Coreias nos dois momentos distintos. As duas seguem estruturas macronarrativas (BARBIERI, 2017, p. 180), privilegiando o conjunto texto e imagem. A proposta é traçar um breve histórico de produção e elencar algumas características principais que comprovam elementos políticos e econômicos de acordo com o contexto da narrativa.

O objetivo é verificar como os países são retratados em relação ao período histórico. Como metodologia será adotada a análise comparativa da representação visual, do estilo narrativo e dos temas abordados.

\section{DISNEY E A COREIA DO SUL}

O italiano Romano Scarpa produziu uma saga "Seul 88" (no original, "Paperolimpiad", em oito capítulos, tratando com humor e utilizando personagens Disney para descrever um romance envolvendo personagens nativos das duas Coreias. No Brasil a saga foi editada em único volume de 244 páginas pela Editora Abril em 12 de agosto de 1988, às vésperas dos Jogos Olímpicos de Seul.

A história em quadrinhos foi lançada em 31 de julho de 1988 na Itália com roteiro e desenho de Romano Scarpa, com arte-final de Luciano Gatto, Maurizio Amendola, Sandro Del Conte e Valerio Held. Ela foi em diversos países como Alemanha, Brasil, Dinamarca, Espanha, Finlândia, Itália, Noruega e Suécia. A história não foi publicada nos Estados Unidos. As oito partes da saga foram publicados em edições diferentes na Itália, porém como capítulos de uma edição única no Brasil, conforme descrito a seguir com o número de páginas:

Seul $1988-31 p$. 
O Silício Violeta Do Deserto - 24p.

A História De Kim Don-Ling E Chen Dai-Lem - 29p.

Um Plano Infalível - 31p.

Caça Aos Ladrões - 26p.

Todos A Seul - 22p.

O Rei Dos Pateróides - 34p.

Os Noivos Olímpicos - 23p.

A saga inicia com o professor Pardal ganhando o prêmio Esnobel e apresentando sua nova invenção, o Vidrium, um cristal ótico derivado do quartzo violeta. Tio Patinhas pede ao inventor que construa lentes quer serão usadas em câmeras de TV durante os Jogos Olímpicos. Porém, quando testadas, as lentes têm o poder de mostrar imagens do futuro.

O primeiro capítulo da saga trata justamente da ideia da construção da lente e da obtenção de sua matéria-prima, o quartzo violeta (Fig. 1). Dentro do contexto da época, as indústrias das telecomunicações e da eletrônica estavam produzindo novos equipamentos com avançadas características técnicas derivadas dos cristais de silício.

A Coreia do Sul, um dos países com maior investimento nesse tipo de indústria, aproveitou os Jogos Olímpicos para exibir e vender essa tecnologia aos países ocidentais. Embora não sem percalços (falhas e problemas técnicos iniciais), os sulcoreanos tiveram sucesso na empreitada, fazendo com que empresas locais tivessem maior penetração em outros países nos anos seguintes. Na saga, a questão tecnológica é destacada diversas vezes em vários momentos. 
Figura 1: Primeiro capítulo destaca a produção de tecnologia avançada em lentes

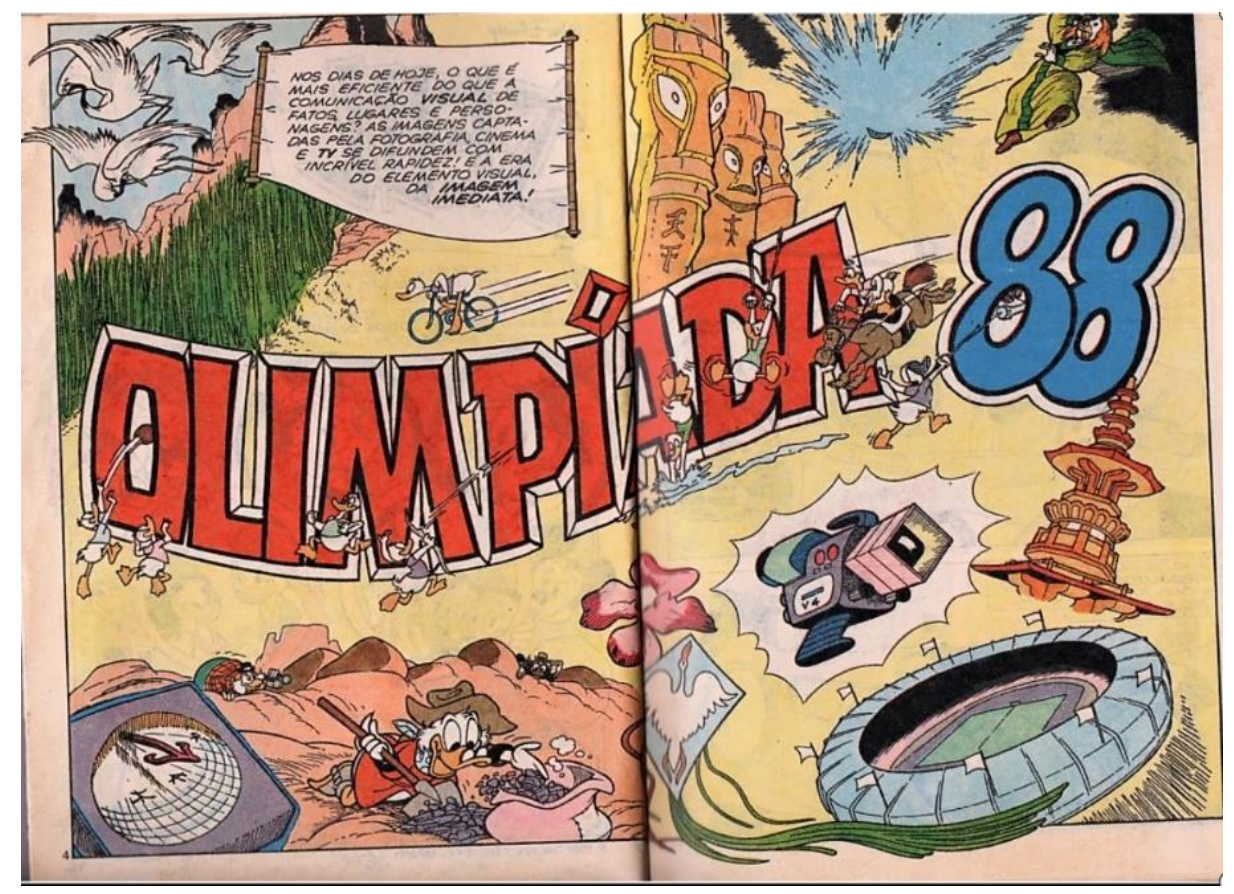

Fonte: OLIMPÍADA 88, 1988, p.4-5.

No segundo capítulo, temos uma típica trama disneyana onde um grupo do bem e um do mal competem entre si. O tema é a escassez da matéria-prima para a produção das lentes de última geração (Fig.2). Tio Patinhas parte em busca do silício violeta no Deserto da Morte, tendo como antagonistas a dupla Brigite e Filomeno e o milionário Patacôncio. A aventura faz alusão também a corrida do ouro na Califórnia.

Uma característica importante é a disputa judicial que é tratada de forma irônica ao fim do capítulo. Há um impasse sobre quem seria o dono da matéria prima. Os personagens recorrem ao sistema judicial, na história simbolizada pelo juiz Salim Parcial. Novamente temos como pano de fundo o contexto da época sobre as disputas judiciais envolvendo patentes e posse de matéria-prima. Na história, o veredito dado pelo juiz é que o silício não pertence a ninguém e, nesta situação, o material deve ficar sob a guarda da Justiça.

O anticlímax é que se descobre que o tal silício em disputa é o errado. O personagem Filomeno pegou o silício ocre (sem valor) e não percebeu por ser daltônico, resultando na ira dos demais personagens. 
Figura 2: A história destaca a busca pela matéria-prima para desenvolver a tecnologia

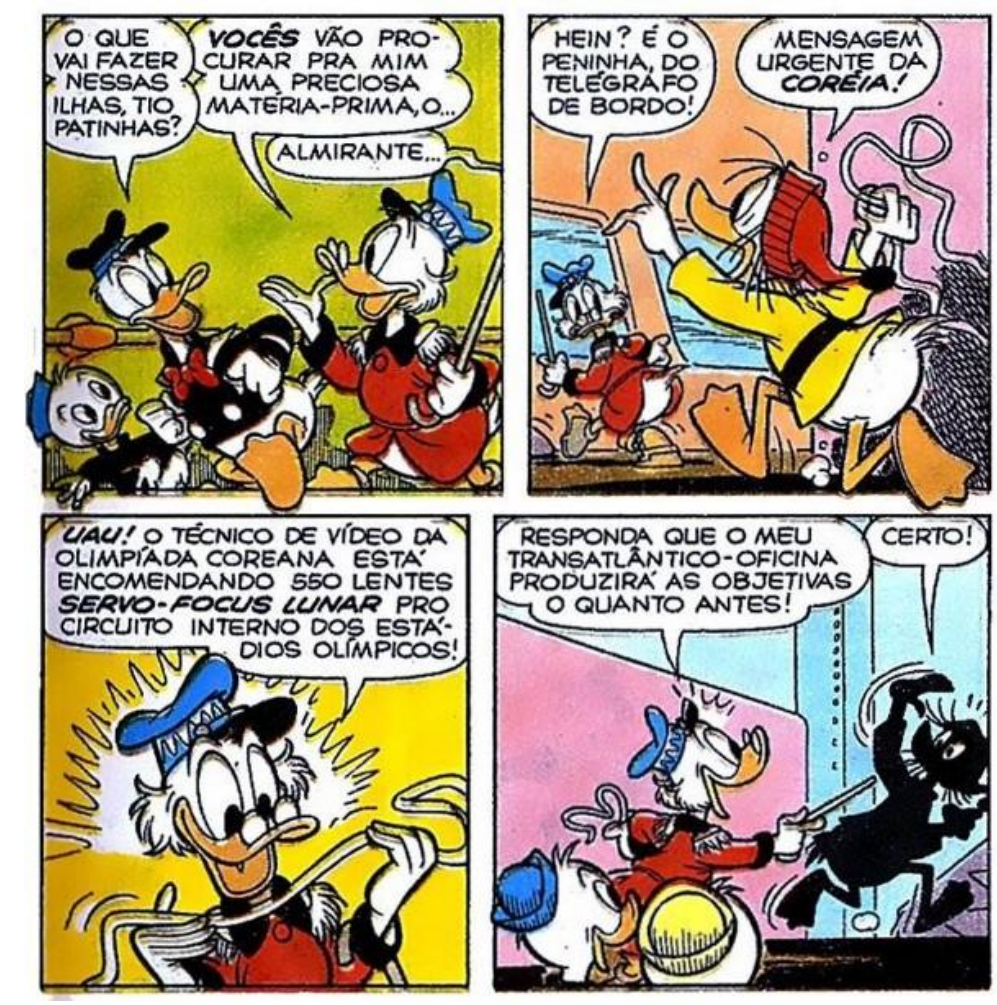

Fonte: OLIMPÍADA 88, 1988, p.13.

O capítulo 3, "A História de Kim Don-Ling e Chen Dai-Lem, traz uma história repleta de significados. Os sobrinhos do Pato Donald, Huguinho, Zezinho e Luisinho, são mostrados conversando com o jovem entregador de jornal, Kim Don-Ling. Ele trabalha meio período como entregador de jornal, é sul-coreano de nascença e, num único quadrinho, afirma que participará dos Jogos Olímpicos na modalidade do voleibol, porém por um "país adotivo". Para ele, no entanto, só existe uma só Coreia. Devido a um incidente envolvendo um dos sobrinhos de Donald, Kim usa um pó misterioso para curar milagrosamente seu olho. É a deixa para o norte-coreano conte a história da Coreia e como, quarenta anos antes, a península foi dividida quase ao meio pelo paralelo 39 (curiosamente os sobrinhos dizem que não estudaram isso). Kim prossegue contando do aumento da rivalidade entre os territórios divididos até que, em 1950, o norte invadiu o sul iniciando guerra que durou anos. Um armistício foi alcançado, porém os países permaneceram divididos e sob forte tensão. 
A rotina da população coreana é ilustrada com a narrativa contada por Kim de quando ele era criança e morava perto da fronteira. Ele iniciou amizade com uma menina que vivia do outro lado da fronteira, Chen Dai-Lem, e começaram a jogar voleibol e a se comunicar usando a muralha de bambus que os separavam. Num determinado dia, um incidente faz com que Kim ultrapasse a fronteira norte e conheça finalmente sua amiga. Não demora para que os guardas de fronteira descubram e a história nos mostra os instrumentos de propaganda norte-coreanos após o retorno bemsucedido de Kim para o lado sul (Fig 3). Uma simples música de flauta tocada por Kim é recebida por uma tuba barulhenta dos soldados do norte. Questionados por Kim o que ocorreu com Chen, a resposta obscura é "Foi transf... isto é, partiu pro norte e não voltará nunca mais! Entendeu?” (OLIMPÍADA 88, 1988, p. 88). O lado místico é mostrado pela relação de Kim com a feiticeira Mae-Wang que o cura com um pó misterioso azul, oriundo da queda de um fragmento de estrela num caldeirão. $O$ final mostra como muitos coreanos emigraram para outros países, como os Estados Unidos, em busca de vida mais tranquila e trabalho estável. Um detalhe notável é que o quadrinhista Romano Scarpa usou os nomes Kim e Chen, bastante comuns na Coreia. O nome Kim é o sobrenome dos ditadores da Coreia do Norte.

Figura 3: A divisão entre as Coreias é ilustrada pela história do casal Kim e Chen
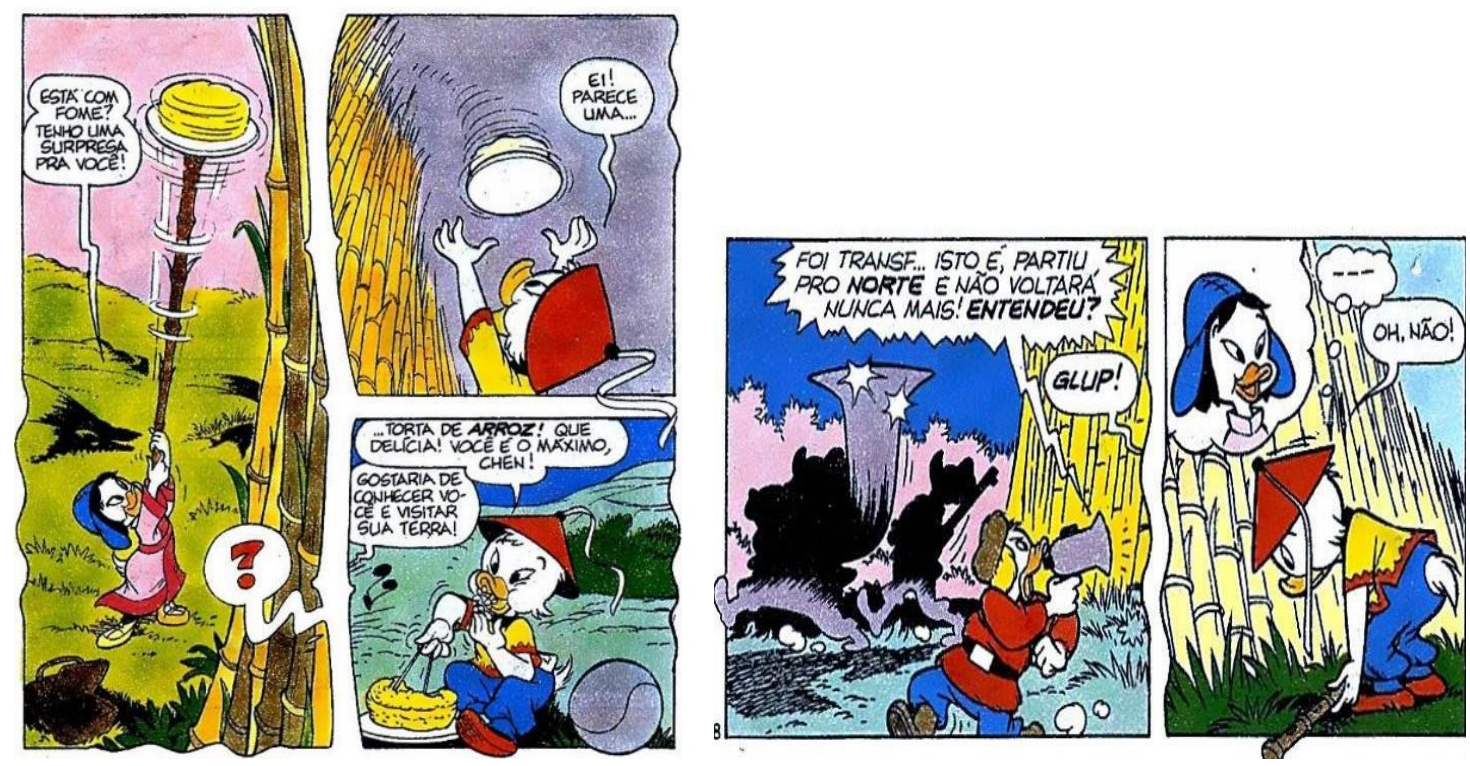

Fonte: OLIMPÍADA 88, 1988, p. 88. 
Os capítulos 4 (Um Plano Infalível) e 5 (Caça aos Ladrões) destacam a revelação de que o pó azul milagroso, usado para curar um dos sobrinhos do Pato Donald, possui propriedades especiais que servem na criação de lentes que mostram o futuro. Tio Patinhas pretende usar uma câmera com as lentes especiais para transmitir os resultados dos Jogos Olímpicos antes que ocorram. O subtexto desta trama que evidentemente trata da busca pelo lucro, tem relação com a discussão comercial sobre os fusos horários. Os eventos esportivos disputados na Ásia ocorrem com 12 horas ou mais de diferença em relação ao oeste da Europa e o continente americano. E a maior audiência está nos Estados Unidos, cujo contrato de exibição é o mais caro dentre as redes de televisão no Comitê Olímpico Internacional. Para os norte-americanos, a vantagem é exibir os jogos em horário nobre no período da noite. Notemos que na votação para escolher a sede dos Jogos Olímpicos de 2016 os Estados Unidos optaram pelo voto na cidade do Rio de Janeiro se a cidade de Chicago perdesse a chance de sediar os Jogos, como de fato aconteceu. Com o evento no Brasil, o público do continente assistiu ao vivo as competições principais.

Há um outro subtexto envolvendo espionagem e roubo de material industrial, quando Bafo de Onça e Tudinha roubam as lentes, forçando Mickey (no papel clássico de detetive) a entrar na trama para recuperar o material.

Nos capítulos 6 (Todos a Seul) e 7 (O Rei dos Pateróides), temos uma demonstração das diferenças entre a Coreia do Sul e a do Norte. O sul é mostrado como tendo tecnologia bastante avançada. Enquanto isso, os norte-coreanos são mostrados desdenhando do sul. A ida dos atletas aos Jogos Olímpicos é encarada como "viagem prêmio" (Fig. 4), tendo em vista que naturalmente a população norte-coreana não tem autorização para fazer tal viagem. O capítulo 7 também lida com a chegada de extraterrestres que se interessam em roubar medalhas. Embora na narrativa esses personagens pareçam gratuitos, é importante destacar que a corrida espacial e o interesse midiático na vida extraterrestre eram temas muito fortes e populares durante a década de $1980^{3}$.

\footnotetext{
${ }^{3}$ Hollywood produziu dezenas de filmes lidando com a corrida espacial, ficção científica no ambiente espacial e extraterrestres. A maior bilheteria da década foi "E.T. o Extraterrestre" (1982) de Steven Spielberg.
} 
Figura 4: A narrativa mostra a ida dos norte-coreanos ao sul como "viagem-prêmio"

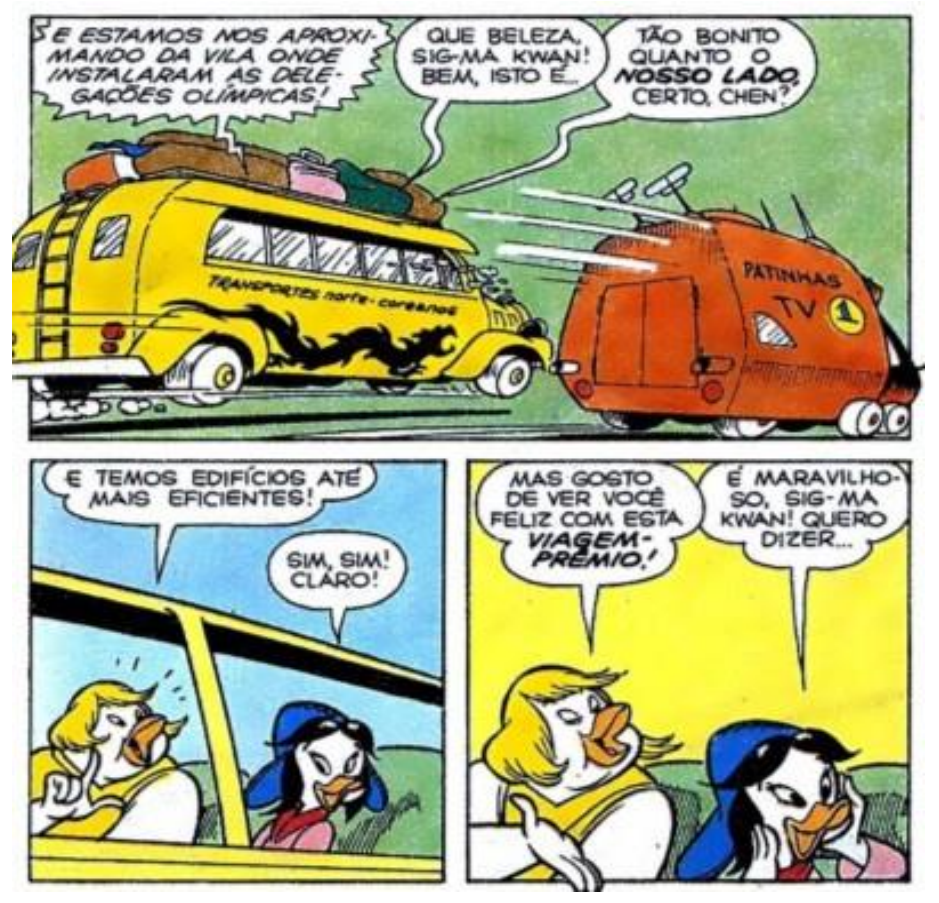

Fonte: OLIMPÍADA 88, 1988, p. 223.

Outro tema citado muito discreta e rapidamente é o doping olímpico. Em dois quatros, a feiticeira eremita Mae lhe entrega o que parece ser uma pílula que o torna mais forte para enfrentar os extraterrestres Pateróides. Os Jogos de Seul 1988 foram palco de um dos mais famosos casos de doping - o do velocista canadense Ben Johnson, flagrado após conquistar a medalha de ouro.

Figura 5: O doping é tratado de forma discreta em somente dois quadros

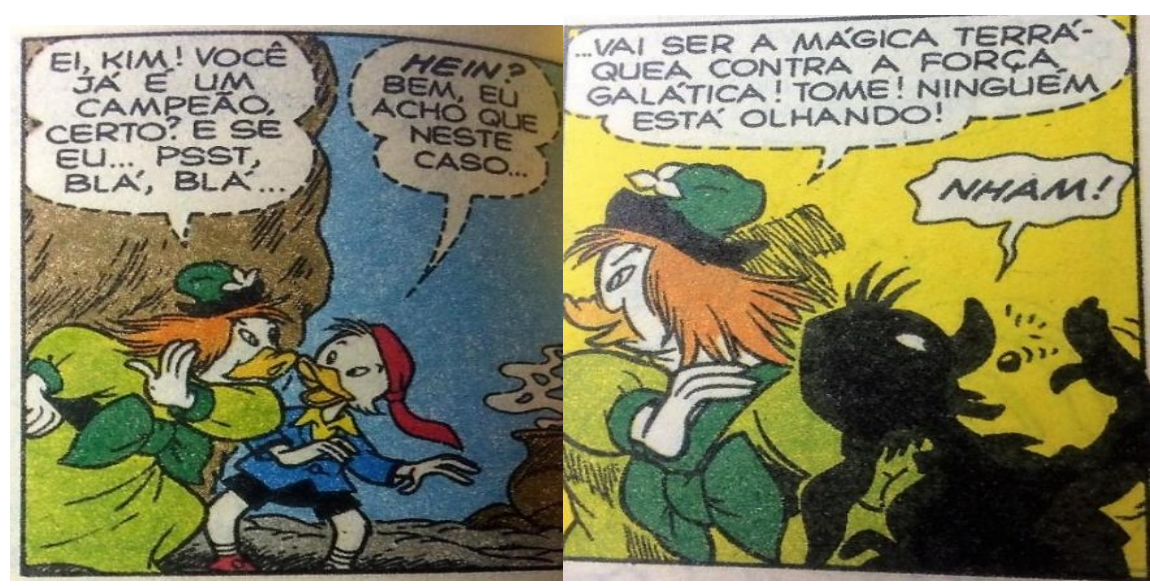

Fonte: OLIMPÍADA 88, 1988, p. 200.

Fronteiras: Revista de História | Dourados, MS | v. 20 | n. 36 | p. 52-70 | Jul. / Dez. 2018 
O capítulo 8 - "Os Noivos Olímpicos” apresenta um final feliz ao casal Kim e Chen, porém a narrativa é centrada na aplicação das lentes que podem ver o futuro. $\mathrm{O}$ resultado é uma série de tropeços e crises na transmissão pela Patinhas TV. Naquele ano, como já afirmamos, a Coreia do Sul buscava mostrar ao mundo ocidental a sua capacidade tecnológica em equipamentos de telecomunicações. Embora tenha ocorrido as tão temidas falhas técnicas, o país foi feliz em exportar para o mundo marcas como LG, Hyundai, Samsung e Daewoo.

\section{UMA VISÃO PARTICULAR DA COREIA DO NORTE}

A segunda obra a ser analisada é a graphic novel "Pyongyang: Uma Viagem à Coreia do Norte" do canadense Guy Delisle, lançada em 2004. Segundo a própria descrição do livro:

Guy Delisle viajou para sua capital, Pyongyang, onde trabalhou como supervisor para um estúdio de animação francês. Nesta graphic novel, o autor traça um retrato irônico e crítico da Coreia do Norte, apresentando seu testemunho singular do país, dos habitantes, dos costumes, da situação de estrangeiro e do regime do então ditador Kim Jong-Il, a única dinastia comunista do mundo. Com a companhia constante e obrigatória de um guia e um tradutor, ele percorre a capital e arredores com seu olhar de artista, vendo além do que é cuidadosamente selecionado para ser apresentado aos raros visitantes estrangeiros (DELISLE, 2007).

Com 192 páginas, a graphic novel é diferente da narrativa disneyana pois se trata de uma visão pessoal, um relato biográfico, descrevendo uma sucessão de situações sobre a realidade de um dos países mais fechados do mundo, a Coreia do Norte (República Popular Democrática da Coreia). O estilo de Delisle contribui para o tipo de narrativa, com seus quadros em preto e branco e diferentes planos ressaltando certas situações de opressão. 
Figura 6: Delisle é retratado na graphic novel. Nesta página se espanta com os rifles de madeira na sala dos animadores

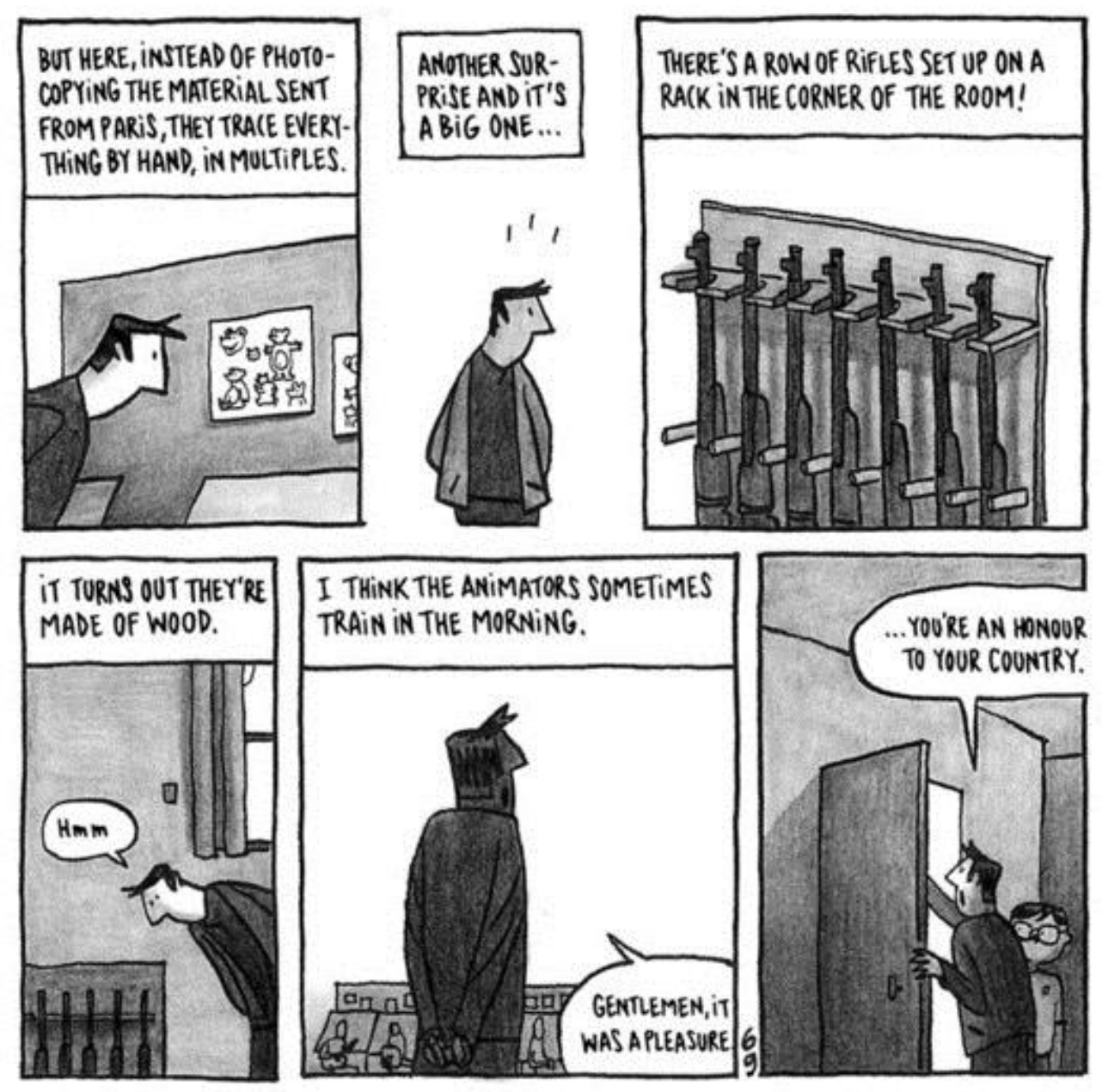

Fonte: DELISLE, 2007, p. 69.

A graphic novel apresenta uma versão do país diferente da imprensa internacional que, por raras vezes, consegue algum acesso as atividades internas da Coreia do Norte. Os jornalistas estão no nível mais baixo de liberdade dentre os visitantes estrangeiros (DELISLE, 2007, p. 122). Essa posição de insider ou alguém privilegiado contribui para que o leitor tenha acesso a certos detalhes que os nortecoreanos desejam esconder dos estrangeiros. Embora apresente ironia e situações cômicas, o relato crítico é relativo, pois Delisle não toma uma posição extremamente crítica, restringindo seus sentimentos aos eventos e situações descritas em sua obra (Fig. 6). Não deixa de ser irônico que, embora a Coreia do Norte sofra intensas sanções 
internacionais, países como a China e a própria França, cujo estúdio de animação enviou Delisle, terceirizem sua produção explorando a mão-de-obra norte-coreana.

Figura 7: Delisle desembarca com o livro "1984” de George Orwell
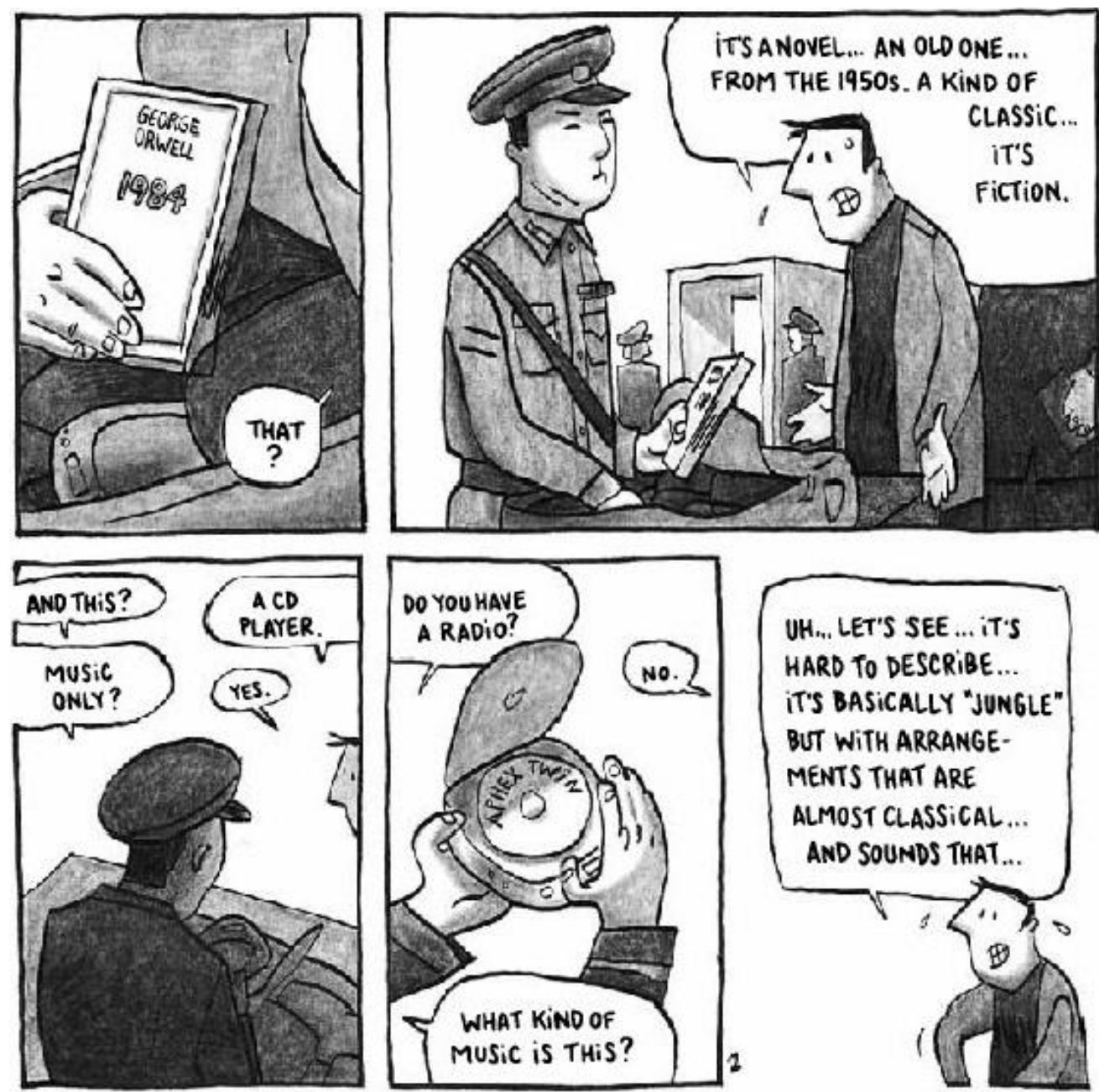

Fonte: DELISLE, 2007, p. 2.

A Coreia do Norte é conhecida por promover uma imagem de aparente organização com uma população devotada ao "grande e querido líder". Se por um lado o autor sentiu-se vigiado pelo Big Brother de George Orwell em seu "1984”, por outro há situações descritas que mostram habitantes que parecem agir sem entender completamente o que fazem. Aliás, a própria obra de Orwell faz parte da narrativa (Fig. 7), pois Delisle viaja para a Coreia do Norte levando consigo um exemplar do livro e o 
empresta para um dos oficiais do prédio onde habita (DELISLE, 2007, p. 40). Em novo encontro, curioso para saber a opinião do coreano sobre Orwell, este oficial lhe devolve rapidamente o livro, alegando que não gostava muito de ficção científica, visivelmente demonstrando o risco de tal obra na Coreia do Norte (DELISLE, 2007, p. 112).

Figura 8: Delisle e todos os estrangeiros são sempre acompanhados por guias-espiões
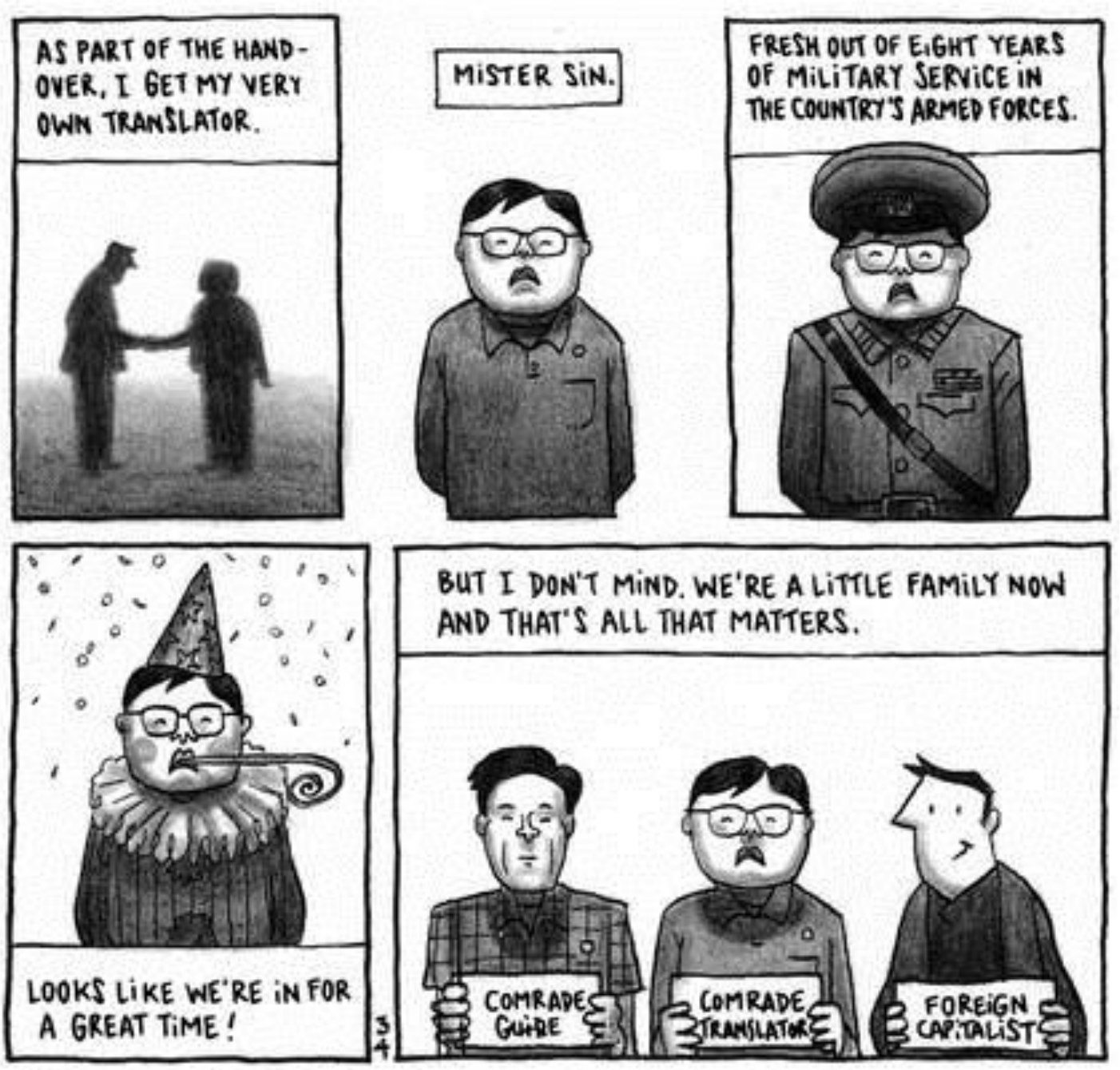

BUT I DON'T MIND. WE'RE A LITTLE FAMILY NOW AND THAT'S ALL THAT MATTERS.

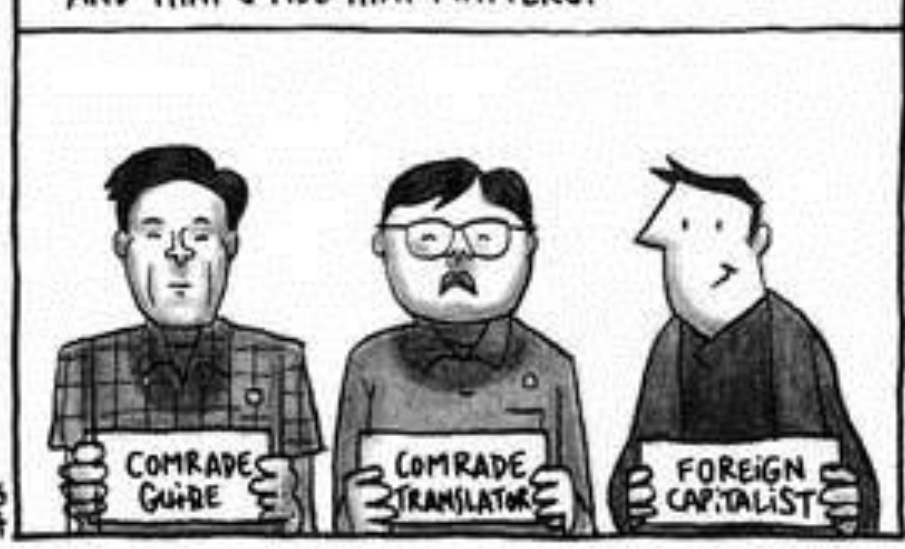

Fonte: DELISLE, 2007, p. 34.

O autor utiliza de um elemento narrativo interativo para brincar, quando em diversos momentos tenta fazer o leitor identificar quem é o espião, mostrando o quão complexo é compreender as diferenças hierárquicas entre os oficiais destacados como 
guias dos estrangeiros (Fig. 8 e Fig. 9), mas que na verdade agem como agentes acompanhantes, destacados para seguir cada passo dos visitantes mesmo em áreas destinadas exclusivamente aos trabalhadores e turistas de outros países. Um dos poucos pontos de maior liberdade era os eventos e festas com o corpo diplomático internacional que reside em um bairro intensamente vigiado.

Figura 9: O autor brinca com o leitor com jogos de identificação do espião

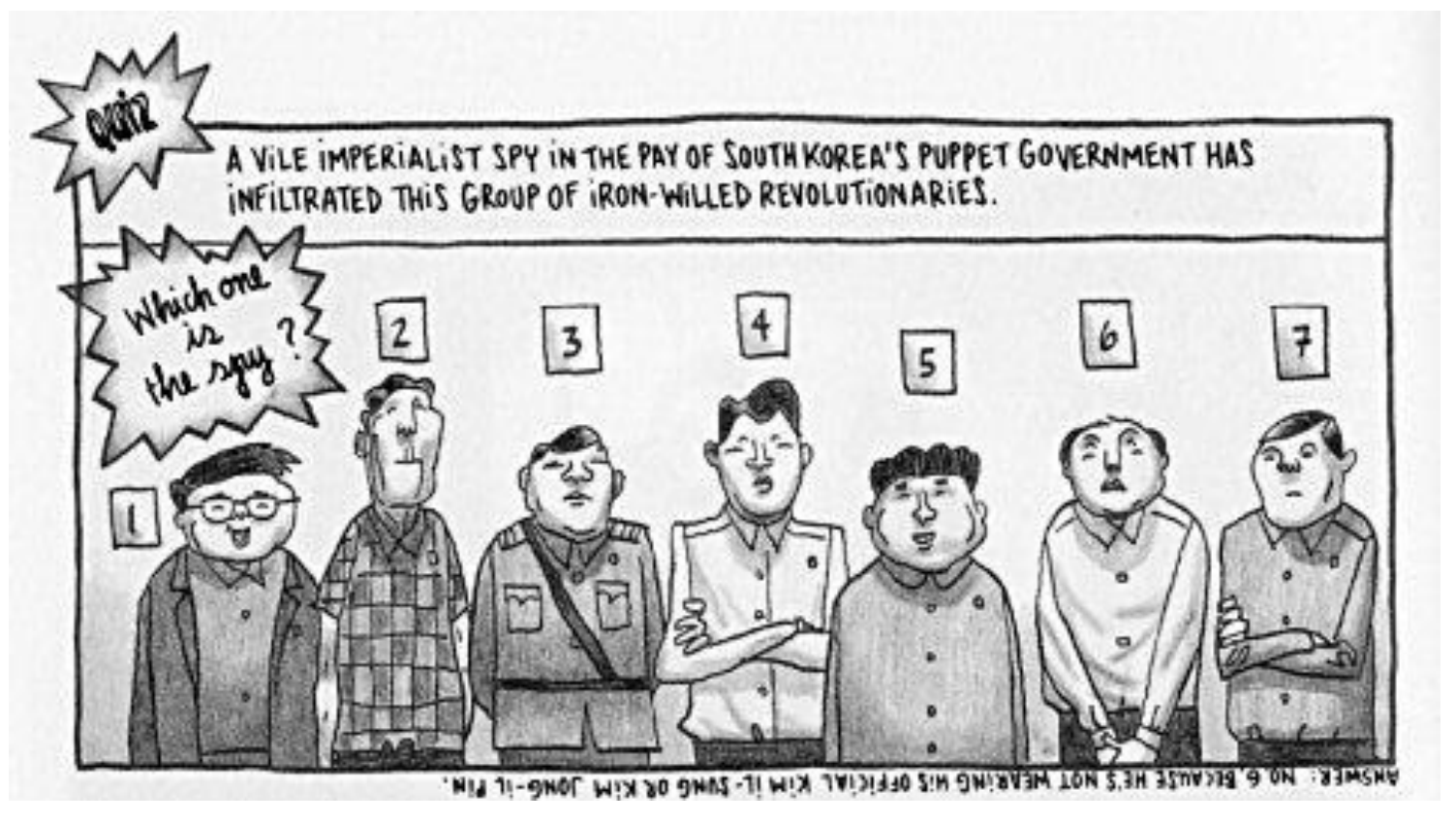

Fonte: DELISLE, 2007, p. 66.

Entre os pontos mais curiosos e até engraçados, Delisle utiliza planos abertos (para demonstrar a grandiosidade e detalhes topográficos) e fechados (para destacar surpresas, padronização, opressão e detalhes bizarros) quando visita os pontos turísticos de Pyongyang (DELISLE, 2007, p. 201). Em diversos momentos, o autor aponta incongruências nas histórias contadas em museus norte-coreanos e a dificuldade existente quando um visitante estrangeiro tenta questionar esses detalhes. Um exemplo é uma foto de um presente dado por um mineiro (uma picareta) ao grande líder. Ao lado da foto está uma picareta diferente da registrada na imagem (Fig. 10). Por mais que um trabalhador estrangeiro até sinta uma aparentemente liberdade, ela é constantemente 
vilipendiada pela opressiva vigilância dos agentes que atuam como guiasacompanhantes.

Figura 10: Delisle mostra as incongruências nas visitas aos pontos turísticas, sem possibilidade de questionamento livre
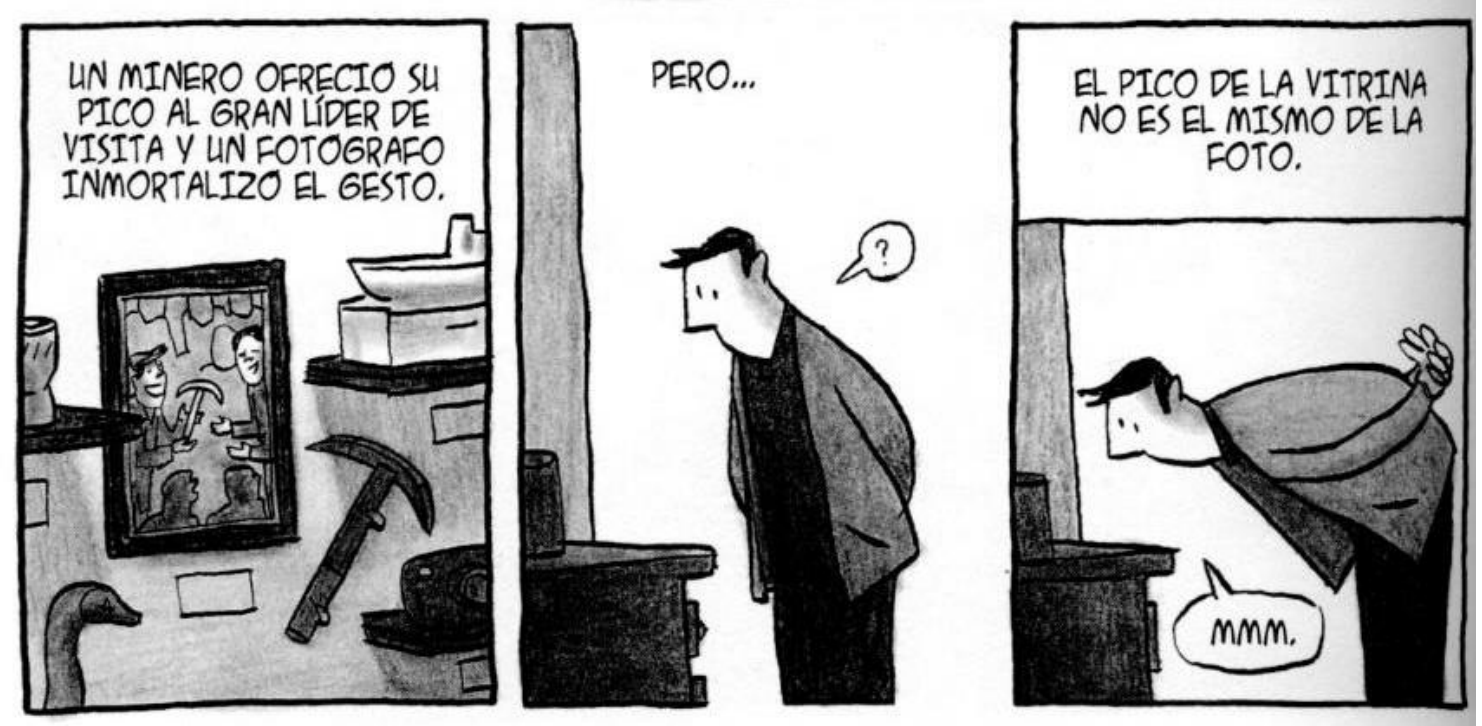

Fonte: DELISLE, 2007, p. 102.

Além do intenso culto ao líder, na obra repetidamente demonstrada pelas numerosas representações dos líderes da família Kim e pelos planos abertos mostrando as gigantescas estátuas e monumentos da capital, a graphic novel também consegue explorar os diferentes estratos sociais dentro de um país comunista, o problema da escassez de alimentos e de energia elétrica, o intenso paradoxo entre a precariedade tecnológica dos civis e o privilégio da elite militar, e como a capital está se modernizando aos poucos devido ao investimento chinês.

\section{DUAS VISÕES}

As duas obras apresentam características distintas sobre contexto, intenções e recepção crítica. A história Disney contém diversas críticas irônicas dentro de um contexto de soft power por parte da Coreia do Sul, que desejava promover a imagem de desenvolvimento das empresas tecnológicas para os países ocidentais. A Coreia do 
Norte, por sua vez, não tem uma intenção definida de soft power. Entretanto, o sistema de vigilância e controle da imprensa indica o interesse histórico do país em controlar o acesso e tudo o que é difundido sobre o país no exterior, em que pese o fato de nem sempre essas informações sejam inteiramente controladas.

A história produzida por Romano Scarpa é uma fantasia colorida no padrão Disney, com narrativa explorando o contexto da Olimpíada e das intenções da Coreia do Sul no plano internacional, não esquecendo de apontar críticas e contradições em torno de evento de tamanha magnitude. Guy Delisle, por sua vez, produziu um relato biográfico em quadrinhos em preto e branco usando diferentes planos e enquadramentos para mostrar ao leitor o choque cultural de um visitante ocidental na Coreia do Norte. Ambas as obras trabalham a complicada ideia da unificação e dos mitos em torno da zona desmilitarizada (na verdade umas das mais fortificadas do mundo) e sua importância geográfica estratégica naquela região do mundo (KAPLAN, 2013, p. 191). No entanto, os dois autores tratam a questão da fronteira de forma próxima da hiperrealidade (ECO, 1994), uma visão quase mítica dos motivos pelos quais as duas Coreias se mantêm separadas ainda na base de um armistício.

Do ponto de vista do consumo, a narrativa disneyana explora o interesse internacional dos Jogos Olímpicos e temas da moda na época (década de 1980) como extraterrestres, novas tecnologias de telecomunicações e doping. Delisle não criou sua graphic novel baseado no interesse do público no momento e sim como forma de divulgar sua própria experiência de vida e de trabalho num dos países mais fechados do mundo. Romano Scarpa explora com sucesso na história disneyana diversos aspectos irônicos do capitalismo e do conflito entre as Coreias, enquanto Delisle também explora as contradições e a opressão, em que pese não tomar posição crítica em sua obra. Consideramos as duas obras como exemplos positivos do entendimento históricopolítico da península coreana e, igualmente, das diferentes formas narrativas de explorar as situações de diferença ideológica, econômica e cultural. 
Fronteiras: Revista de História

As duas Coreias nos quadrinhos: representação dos países no olhas do Ocidente

Celbi Vagner Melo Pegoraro

\section{CONSIDERAÇÕES FINAIS}

Do ponto de vista gráfico e narrativo, ambas das histórias apresentam elementos que reforçam os elementos críticos pelo uso ou da ausência de cor, da dinâmica dos planos abertos e fechados e da própria ironia na ação de seus personagens. Um destaque é o fato das duas obras desenvolverem de forma eficiente ações que demonstram as relações políticas e econômicas das Coreias em relação aos países ocidentais.

Os dois autores não produziram obras estritamente críticas, embora possamos constatar - talvez um pouco mais na obra de Scarpa - elementos que nitidamente comprovam conflitos, contradições, desigualdades e provocações em relação aos costumes ou ao contexto das situações da época em que as histórias foram produzidas.

As obras analisadas possibilitam observar como os autores Romano Scarpa e Guy Delisle trabalham de forma apropriada os elementos políticos e de propaganda das duas Coreias em seus respectivos períodos históricos. Podemos evidenciar a possibilidade de produzir narrativas cativantes com elementos políticos e, de forma inversa, como o leitor pode aprender características da realidade social de ambos os países em contextos singulares.

\section{REFERENCIAS}

ARRIGHI, Giovanni. O Longo Século XX. Rio de Janeiro: Contraponto, 1996.

BARBIERI, Daniele. As Linguagens dos Quadrinhos. São Paulo: Peirópolis, 2017.

DELISLE, Guy. Pyongyang: Uma viagem à Coreia do Norte. Campinas/SP: Zarabatana Books, 2007.

ECO. Umberto. Viagem na Irrealidade Cotidiana. Rio de Janeiro: Nova Fronteira, 1994.

HOBSBAWN, Eric. Era dos Extremos: O breve século XX 1914 - 1991. São Paulo: Companhia das Letras, 1995.

KAPLAN, Robert. A Vingança da Geografia. Rio de Janeiro: Elsevier, 2013. 
KEGLEY Charler e Eugene WITHKOPH. World Politics: Trends and Transformation. 10th edition. Belmont: Thomson Wadswoth, 2006.

NYE, Joseph. Soft Power: The Means to Success in World Politics. New York: PublicAffairs, 2005.

OLIMPÍADA 88. São Paulo: Editora Abril, 1988.

WAACK, William. Conferências de Yalta e Potsdam (1945). In: MAGNOLI, Demétrio (Org.). História da Paz: os tratados que desenharam o planeta. São Paulo: Contexto, 2008. p. 269-296.

Recebido em: 10/11/2018

Aprovado em: 31/01/2019 